\title{
Breast manifestations of systemic diseases
}

This article was published in the following Dove Press journal:

International Journal of Women's Health

4 February 2012

Number of times this article has been viewed

\section{Christina A Dilaveri \\ Maire Brid Mac Bride \\ Nicole P Sandhu \\ Lonzetta Neal \\ Karthik Ghosh \\ Dietlind L Wahner-Roedler \\ Division of General Internal Medicine, Mayo Clinic, Rochester, MN, USA}

Correspondence: Christina A Dilaveri Division of General Internal Medicine, Mayo Clinic, 200 First St SW, Rochester, MN 55905, USA

Email dilaveri.christina@mayo.edu

\begin{abstract}
Although much emphasis has been placed on the primary presentations of breast cancer, little focus has been placed on how systemic illnesses may affect the breast. In this article, we discuss systemic illnesses that can manifest in the breast. We summarize the clinical features, imaging, histopathology, and treatment recommendations for endocrine, vascular, systemic inflammatory, infectious, and hematologic diseases, as well as for the extramammary malignancies that can present in the breast. Despite the rarity of these manifestations of systemic disease, knowledge of these conditions is critical to the appropriate evaluation and treatment of patients presenting with breast symptoms.
\end{abstract}

Keywords: breast, endocrine, hematologic, infectious, vascular

\section{Introduction}

Although breast cancer is the most worrisome problem involving the breast, systemic illnesses can affect the breast and cause concern related to diagnosis and treatment. In this article, we focus on the varying impact of different systemic illnesses on breast tissue.

Women exhibiting breast manifestations of systemic disease may present with a breast lump, skin changes, focal pain, and/or mammographic abnormalities. Evaluation of these symptoms depends on the overall presentation and may include diagnostic mammogram, breast ultrasound, biopsy of suspicious lesions, and, in some cases, magnetic resonance imaging of the breast. After exclusion of a primary breast malignancy or benign primary breast lesion, one must consider evaluation for systemic disease. This article provides an overview of breast manifestations of systemic disease and their evaluation.

\section{Endocrine disease Diabetic mastopathy}

Diabetic mastopathy typically presents as a palpable breast mass that may be nontender, solitary or multiple, and unilateral or bilateral. It is most commonly identified in premenopausal women with long-standing type 1 diabetes mellitus. ${ }^{1-3}$ Diabetic mastopathy accounts for less than $1 \%$ of benign breast disease but can be present in up to $13 \%$ of patients with type 1 diabetes. ${ }^{4}$ There have also been reports of diabetic mastopathy in older women in association with long-standing type 2 diabetes mellitus, ${ }^{5}$ but this finding was not reproduced in another retrospective cross-sectional study. ${ }^{3}$ Some cases have been identified in nondiabetic patients as well. Although the etiology of diabetic mastopathy 
is poorly defined, it remains debatable as to whether it is actually a complication of diabetes mellitus. The lesions may spontaneously regress but the likelihood of recurrence is fairly high. ${ }^{1}$ There is no associated breast cancer risk.

On mammography, diabetic mastopathy is typically seen as a solid mass with asymmetric density, or it may appear as architectural distortion with features highly suggestive of malignancy. On sonograms, the lesions have a concerning appearance, most often irregular hypoechoic masses with worrisome features (Figure 1). If the patient has a known history of diabetes mellitus, it is possible to make the diagnosis of diabetic mastopathy on core needle biopsy, thus eliminating the need for an excisional biopsy. Magnetic resonance scanning of the breast has no role yet in establishing the diagnosis of diabetic mastopathy.

Diabetic mastopathy is a fibroinflammatory proliferation of breast tissue. Microscopic findings of lymphoid infiltrate of the periductal, perilobular, and perivascular structures are variably observed and may be patchy. In addition, dense keloid fibrosis is generally seen ${ }^{6}$ (Figure 2).

Excision of diabetic mastopathy is rarely necessary. There are no measures known to prevent its development or to lead to its resolution. Routine clinical examination is recommended and, in patients with a documented history of diabetic mastopathy, new occurrences can generally be managed conservatively unless suspicion of malignancy is raised on imaging. ${ }^{7}$

\section{Vascular disease Calciphylaxis}

The rare, systemic medial calcification of arterioles, leading to ischemia and subcutaneous necrosis, has been labeled "calciphylaxis." This condition occurs most commonly in patients who have end-stage renal disease and are on hemodialysis or who have undergone renal transplantation recently. ${ }^{8}$ Only a few cases of calciphylaxis occurring in the breast have been reported in the medical literature, ${ }^{9}$ with six cases involving the breast after internal mammary artery harvesting. Five of these six patients were on dialysis for end-stage renal disease. ${ }^{10-12}$ Breast findings included erythematous skin, peau d'orange, and large areas of ischemic necrosis. ${ }^{9}$

Mammographic findings include multiple and diffuse bilateral calcifications with dystrophic or vascular morphology ${ }^{13}$ and trabecular thickening indicative of parenchymal edema. ${ }^{14}$ Ultrasonographic changes include tissue edema and shadowing foci suggestive of extensive macrocalcification. ${ }^{14}$ Definitive diagnosis requires a biopsy.

Breast biopsy findings include fat necrosis, fibrosis, calcium deposits in the vessel walls, and calcifications of nonvascular tissue. The differential diagnosis includes breast cancer, especially inflammatory breast cancer. Most cases of calciphylaxis of the breast are treated with partial or total mastectomy. Complete healing of the breast lesion has been reported with total parathyroidectomy. ${ }^{13}$

\section{Diffuse dermal angiomatosis}

Diffuse dermal angiomatosis is a rare, acquired, cutaneous, reactive vascular disorder that was first described in $1994 .^{15}$ The benign vascular proliferation is characterized by poorly circumscribed, erythematous to violaceous painful lesions with frequent ulceration generally involving the extremities of patients who have severe vascular disease and other comorbid conditions. Diffuse dermal angiomatosis involving the breast is characterized by painful, violaceous, nonhealing,

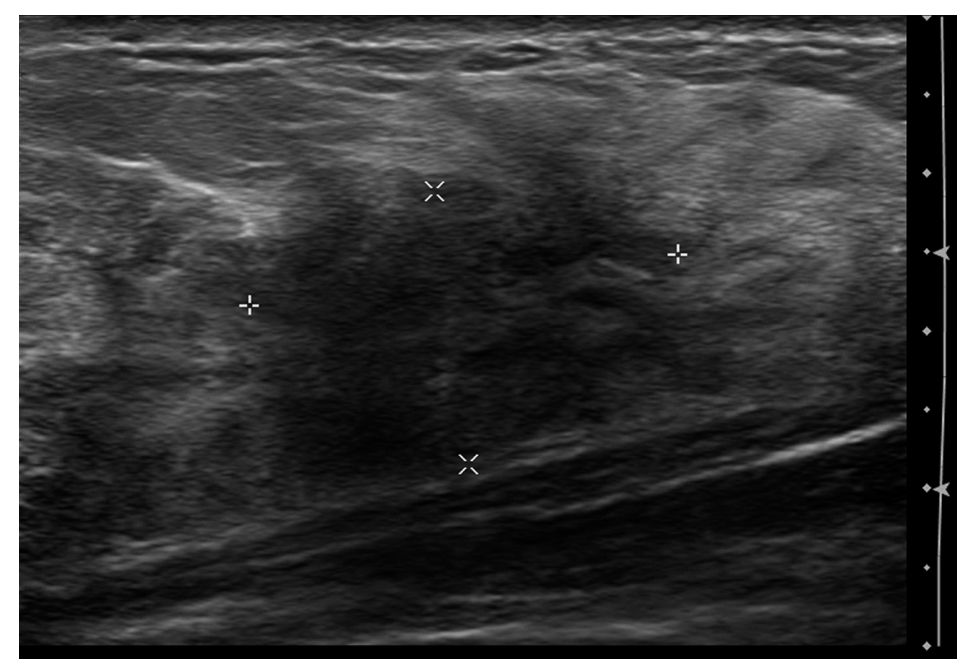

Figure I Diabetic mastopathy: ultrasound of a palpable abnormality shows an ill-defined mass-like area with decreased echogenicity and concerning features. 


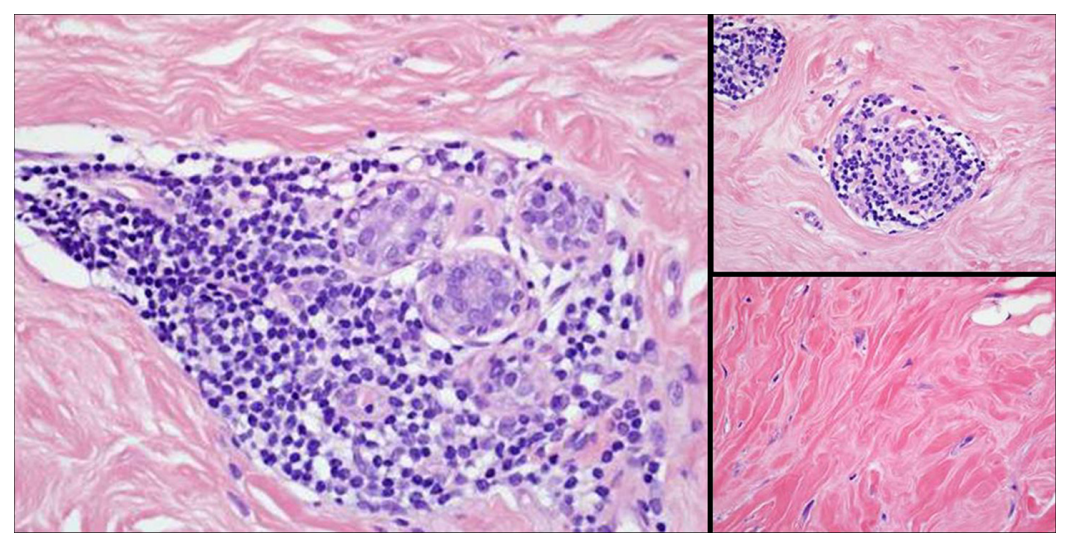

Figure 2 Breast biopsy showing lymphocytic mastitis consistent with diabetic mastopathy. Hematoxylin-eosin stains: Left, original magnification 400x; right top, original magnification 400x; right bottom, original magnification 400x.

ulcerating macules arising from an erythematous background on both breasts. The vascular-like lesions preferentially involve the underside of the breast. ${ }^{16-19}$ No specific findings on mammogram or ultrasound have been described in the medical literature. The diagnosis is made by punch biopsy of the skin lesion. The characteristic histologic features of diffuse dermal angiomatosis are the diffuse extravascular, interstitial proliferation of endothelial cells within the dermal stroma. An immunohistochemical stain for CD31 can be obtained for confirmation. Focal areas of proliferating cells may show an epithelioid morphology, vacuolated cytoplasm, and formation of small vascular channels. ${ }^{20}$ Treatment with isotretinoin, which has an antiangiogenic effect, has been reported to be beneficial in diffuse dermal angiomatosis involving the breast. ${ }^{16}$

\section{Cardiovascular disease}

The prevalence of breast arterial calcification in women presenting for screening mammography has been reported to be about $14 \% .{ }^{21}$ No clinical breast findings have been associated with breast arterial calcification detected by mammography. However, the presence of breast arterial calcification on mammograms indicates a substantially increased risk for development of cardiovascular disease or stroke. When an arterial wall is imaged longitudinally, breast arterial calcification can be detected along the periphery of a tapered structure as two straight parallel calcium deposits (Figure 3). In contrast, when an arterial wall is imaged en face, breast arterial calcification can have a calcific ring configuration typical of arteries and distinct from breast ducts. ${ }^{21}$ Mammography is diagnostic for breast arterial calcification, and breast biopsies are not indicated for it. The pathologic findings of arterial calcifications in breast arterial vasculature are similar to those of cardiovascular disease. On mammograms, breast arterial calcification is an incidental finding and no specific treatment is indicated. However, since breast arterial calcification on a mammogram may be considered to be a marker for development of cardiovascular disease, risk stratification and risk factor counseling are advisable. ${ }^{21}$

\section{Systemic inflammatory disease Giant cell arteritis}

Although giant cell arteritis is a systemic disease, on rare occasions the breast may be the primary organ of manifestation. In a review of the English medical literature up to 2008 , Kadotani et al $^{22}$ identified 20 reported cases, all of which were postmenopausal elderly women. Single or multiple lumps due to arteritis were present in $80 \%$ (16 of 20 patients), and redness and tenderness in the absence of lumps were present in $10 \%$. Breast involvement was bilateral in $50 \%$ of the patients. Spontaneous breast pain and tenderness were presenting features in $85 \%$ of the patients. ${ }^{22}$ Systemic symptoms such as low-grade fever, arthralgia, myalgia, and those suggestive of polymyalgia rheumatica were present in $65 \%$ of the patients.

There have been no reports of mass lesions or other distinctive findings by mammography or ultrasonography. In a recent case report ${ }^{23}$ of a patient presenting with a lump in her breast and a negative mammogram, ultrasound of a stringlike thickening in the right axillary tail of the breast revealed a "halo sign" (hypoechoic circumferential wall thickening indicating edema), which, compared with biopsy, has been reported to have a sensitivity of $69 \%$ and a specificity of $82 \%$ for diagnosis of arteritis. ${ }^{24}$ In most cases reported in the medical literature, the diagnosis was made after excisional biopsy (a considerable amount of tissue is required to make the diagnosis of giant cell arteritis). In rare cases, the diagnosis was established before biopsy on the basis of 

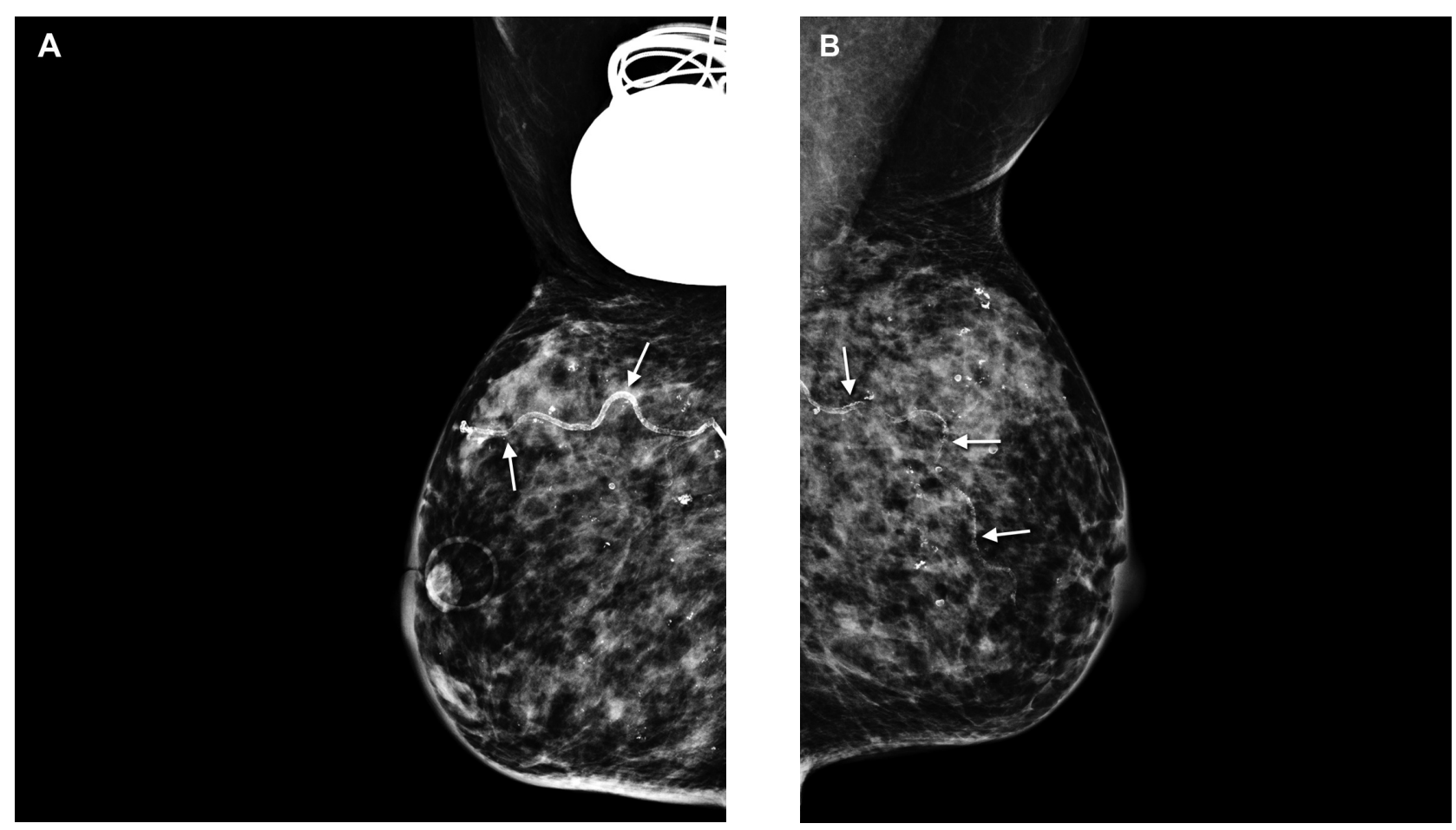

Figure 3 Bilateral mammogram showing benign arterial calcifications. (A) Right mediolateral oblique view shows arterial calcification (arrows) and (at top right of image) a pacemaker. (B) Left mediolateral oblique view shows arterial calcification (arrows).

systemic symptoms ${ }^{22}$ and ultrasound findings. ${ }^{23}$ Pathology shows fragmentation of the elastica in association with giant cell infiltration, intimal proliferation, and narrowing of the vascular lumina. Inflammatory cancer was suspected in four of seven cases reported by Kadotani et al. ${ }^{22}$

Prednisone is the treatment of choice. It has been shown to improve both general symptoms and breast-specific manifestations of giant cell arteritis. ${ }^{22}$

\section{Polyarteritis nodosa}

Polyarteritis nodosa of the breast is rare, with about a dozen cases reported in the medical literature. ${ }^{25}$ The clinical presentation ranges from localized disease involving the breast (skin and/or parenchyma) to breast manifestations as part of systemic polyarteritis nodosa. Polyarteritis nodosa can mimic breast cancer in patients presenting with a mass, and it can mimic breast infections such as mastitis or necrotizing fasciitis.

Imaging modalities have not been very helpful in establishing the diagnosis. Mammographic findings have not been reported in all cases, and those that have been reported have been negative except for findings in two ${ }^{25,26}$ patients who had calcification of arteries in both breasts as a prominent feature. The diagnosis of polyarteritis nodosa involving the breast is made by evaluating an adequate tissue sample from the breast.
Polyarteritis nodosa is characterized by segmental transmural inflammation of muscular arteries. Polymorphonuclear leukocytes and mononuclear cells are found in the cellular infiltrate. Leukocytoclasis may also be noted. Arterial wall necrosis results in fibrinoid necrosis, which has a homogeneous, eosinophilic appearance. Disruptions of the internal and external elastic lamina may contribute to the development of aneurysmal dilatation. Lesions that appear to be of different ages are typically found within a single sample. ${ }^{27}$ Polyarteritis nodosa mimics breast cancer, inflammatory carcinomatosis, or breast infections, such as mastitis and necrotizing fasciitis.

Treatment of polyarteritis nodosa is guided by how the patient with disease presents. Débridement of localized necrotic skin and necrotic mammary tissue may be necessary to manage the defect. If a tissue biopsy confirms the diagnosis of polyarteritis nodosa, then immunosuppressive treatment can commence. ${ }^{25}$

\section{Wegener's granulomatosis}

Breast involvement is rare in patients with the uncommon disease of Wegener's granulomatosis. Approximately 28 cases of breast involvement have been reported as occurring in women between the third and seventh decades of life. ${ }^{28}$ Breast involvement may occur as the presenting symptom of Wegener's granulomatosis or as a synchronous or metachronous lesion in 
patients with systemic disease. Presenting symptoms include unilateral or bilateral breast masses, breast abscesses, necrotic lesions, and ulcerations. ${ }^{28,29}$

Mammographic findings have been reported as ill-defined or irregular masses suspicious for carcinoma. ${ }^{30}$ Ultrasonographic findings include irregular hypoechoic masses. ${ }^{30}$ The diagnosis is made by breast biopsy, but it can be difficult to establish if there are only small fragments of core needle biopsy material available versus an adequate tissue specimen.

Wegener's granulomatosis is characterized by vasculitis of the medium-sized vessels that affects capillaries, venules, arterioles, and arteries. Necrotizing granulomatous inflammation with central necrosis is the hallmark of the disease. ${ }^{28}$ Associated with the granulomatous inflammation are multinucleated giant cells, plasma cells, lymphocytes, and neutrophils. Wegener's granulomatosis may mimic breast cancer or granulomatous mastitis.

The initial treatment of most patients described in the medical literature has been corticosteroids and cyclophosphamide. In several cases, patients underwent excision of the breast lesion or a mastectomy. In almost all cases, symptoms improved substantially after immunosuppressive therapy. ${ }^{28}$

\section{Sarcoidosis}

Sarcoidosis is characterized as a systemic granulomatous disorder with no known etiology that can involve any organ system but frequently affects the lungs, hilar lymph nodes, eyes, skin, and joints. Breast involvement is rare, occurring in less than $1 \%$ of cases. ${ }^{31}$ Breast involvement can be either the sole manifestation, which is termed "primary mammary sarcoidosis," or it can be part of a more obvious systemic disease. Patients may present either with a mass or without symptoms but with a mass detected on a mammogram. ${ }^{32}$

The mammographic abnormality is typically a mass, asymmetry, or an area of architectural distortion. ${ }^{33,34}$ Mammographic and ultrasonographic features are usually worrisome for malignancy. Biopsy, either surgical or imageguided core needle, is required for diagnosis. Pathologic findings are noncaseating granulomas. Giant cells may or may not be seen. The differential diagnosis includes idiopathic granulomatous mastitis, tuberculosis, fungal infection, cat-scratch disease, and other autoimmune disorders with granulomatous inflammation. ${ }^{32}$

The usual first-line therapy is systemic corticosteroids. For patients with disease solely in the breast who do not respond to corticosteriods, there may be a role for surgical excision although this has not been established as a first-line therapy. ${ }^{31}$

\section{Lupus mastitis}

Lupus mastitis occurs in approximately $2 \%$ of patients with systemic lupus erythematosus. ${ }^{35} \mathrm{Up}$ to $70 \%$ of patients have associated discoid skin lesions. Lupus mastitis is rarely the presenting symptom. Fewer than 25 cases have been described in the medical literature, with four cases reported in men. Breast findings on clinical examination include single or multiple subcutaneous nodules, which may be tender or painful and can progress to ulcerated lesions. ${ }^{35}$

The lesions are ill-defined on mammograms and sonograms and may or may not be associated with calcifications. Alternatively, calcifications may be present alone, which is suggestive of fat necrosis. ${ }^{35}$ Image-guided or excisional biopsy is needed to differentiate this lesion from breast cancer.

Pathologically, immune complex depositions are noted at the basement membrane of the dermal-epidermal junction and in the blood vessels in the area of the panniculitis. ${ }^{35}$ Key histopathologic findings are lobular lymphocytic panniculitis and hyaline fat necrosis. ${ }^{36}$ Lymphocytic vasculitis is also a common feature.

If insufficient biopsy tissue is present, the lesion may be mistaken for primary medullary carcinoma of the breast, especially if the tissue contains predominantly lymphoplasmacytic inflammatory component. Diabetic mastopathy may also be in the differential diagnosis. ${ }^{35}$

Initial treatment typically consists of antimalarial agents or corticosteroids. Surgery can be considered in cases that do not respond to medical treatment. ${ }^{36}$

\section{Infectious disease}

Breast involvement in systemic infections is a rare condition but has been reported with tuberculosis, echinococcosis and other parasitic diseases, and actinomycosis. Breast tuberculosis may become a relevant problem with the increasing occurrence of tuberculosis related to acquired immune deficiency syndrome and tuberculosis as a global health concern.

Tuberculosis of the breast is a rare condition generally secondary to systemic infection, with breast tissue infection resulting from hematogenous lymphatic spread or from spread from a contiguous infection such as one in the chest wall. ${ }^{37,38}$ Clinical presentation is generally a breast lump that is firm to hard in consistency and can be mistaken for malignancy, but it can also present as an ulcer or a discharging sinus on the skin overlying the breast, as a nipple discharge, or as peau d'orange if it is associated with extensive axillary disease. 
Mammography is often inconclusive because the lesion may be seen as a round mass with ill-defined margins. On ultrasound, lesions are often hypoechoic or present as complex cysts. Ultrasound-guided cyst aspiration with cytology of the fluid may show epitheloid cell granulomas and necrosis but is often inconclusive. Histopathologic findings of biopsy specimens of the mass demonstrate necrotizing granulomas.

Treatment of tuberculosis infection of the breast is with multidrug antitubercular therapy. Surgical intervention is needed only for drainage of a breast abscess or for incisional or excisional biopsy of the mass. In some instances, a residual breast mass after antitubercular therapy may require surgical excision. ${ }^{37}$

\section{Hematologic disease Malignant lymphoma}

Lymphoma of the breast can present as primary lymphoma, implying that there is no extramammary organ involvement, and as secondary lymphoma with known extramammary disease. Both conditions are rare, with primary breast lymphoma comprising about $0.1 \%-0.5 \%$ of all breast neoplasms and secondary breast lymphoma being slightly more common. ${ }^{39}$ Primary lymphoma can present as diffuse infiltration or as discrete and sometimes multiple nodules. Wong et $\mathrm{al}^{39}$ reviewed the Mayo Clinic experience with primary non-Hodgkin's lymphoma of the breast over 25 years (1973-1998) and identified 26 patients, 25 of whom were women with a median age of 60 (range 12-80) years at diagnosis. Twenty-four of the 26 patients presented with a breast lump. The median tumor size was 3.3 (range 1-10) $\mathrm{cm}$. In contrast with tumors in primary breast lymphoma, breast masses in secondary breast lymphoma have been reported to be smaller, perhaps because of the shorter duration of the disease within the breast. ${ }^{40}$

Sabate et $\mathrm{al}^{40}$ noted significant differences between breast lymphoma and carcinoma on mammograms. The mean size of the tumor was larger in patients in the lymphoma group ( $4.6 \mathrm{~cm}$ versus $2-3 \mathrm{~cm}$ in patients in the carcinoma group). Architectural distortion was not noted in the lymphoma masses but was evident in the carcinoma group. Calcifications were not observed in any patients in the lymphoma group but were evident in $50 \%$ of those in the carcinoma group. Although a core biopsy may be adequate for diagnosis of a breast lymphoma, an excisional biopsy may be necessary to obtain adequate tissue for lymphoma subtyping.

Most primary breast lymphomas are non-Hodgkin's lymphoma. Although all histologic types of lymphoma have been described, primary breast lymphomas are most commonly B-cell lymphomas; about one-half are diffuse large B-cell lymphomas. Less common are breast lymphomas with an indolent histology (ie, follicular non-Hodgkin's lymphoma or extranodal marginal zone lymphoma).

Treatment consists of local excision of the breast lymphoma, radiotherapy, and chemotherapy. The choice of chemotherapy is based on the histologic subtype. Mastectomy does not appear to improve survival. ${ }^{41}$

\section{Plasmacytoma}

Plasmacytoma may present as a palpable breast mass or, more unusually, as an incidental finding on mammography. It may occur as the initial presentation or in the setting of known multiple myeloma. ${ }^{42,43}$ In contrast with solitary plasmacytoma of the bone, extramedullary plasmacytoma is associated with symptomatic multiple myeloma in only $15 \%$ of patients. ${ }^{44}$

Mammographic findings include rounded, oval, and lobulated masses, which can be solitary or multiple or both (Figure $4 \mathrm{~A}$ and B). Occasionally, they present as diffuse infiltration of the breast. Ultrasound typically shows a hypoechoic mass that can be either well defined or ill defined (Figure 4C). ${ }^{42}$ Core biopsy is needed to differentiate plasmacytoma from primary breast cancer. Immunohistochemical staining reveals clonal plasma cells (Figure 5A) positive for $\kappa$ or $\lambda$ light chains ${ }^{44}$ (Figure 5B).

Treatment consists of radiotherapy to the extramedullary plasmacytoma, ${ }^{44}$ unless there is significant systemic multiple myeloma, in which case treatment is for the systemic disease.

\section{Amyloid}

Amyloid of the breast is either localized or more commonly associated with systemic amyloidosis. As part of the systemic form, breast amyloid usually occurs as a late presentation of known amyloidosis in other visceral organs. In a case series from Boston Medical Center, Charlot et $\mathrm{al}^{45}$ found that localized amyloidosis of the breast represented only $0.5 \%$ of all the patients referred to the amyloid treatment center. Patients may present with either a breast mass ${ }^{40,46,47}$ or no breast findings on clinical examination. ${ }^{48}$

Mammographic findings include incidental masses, clustered microcalcifications, and focal asymmetry. ${ }^{49}$ Core needle biopsy or excisional biopsy aids diagnosis. Macroscopic examination of biopsy specimens shows well-circumscribed solid gray tumors, whereas microscopic examination shows abundant hyaline pink material. Focal microcalcifications may be apparent, and amyloid stains are positive. ${ }^{50}$ 

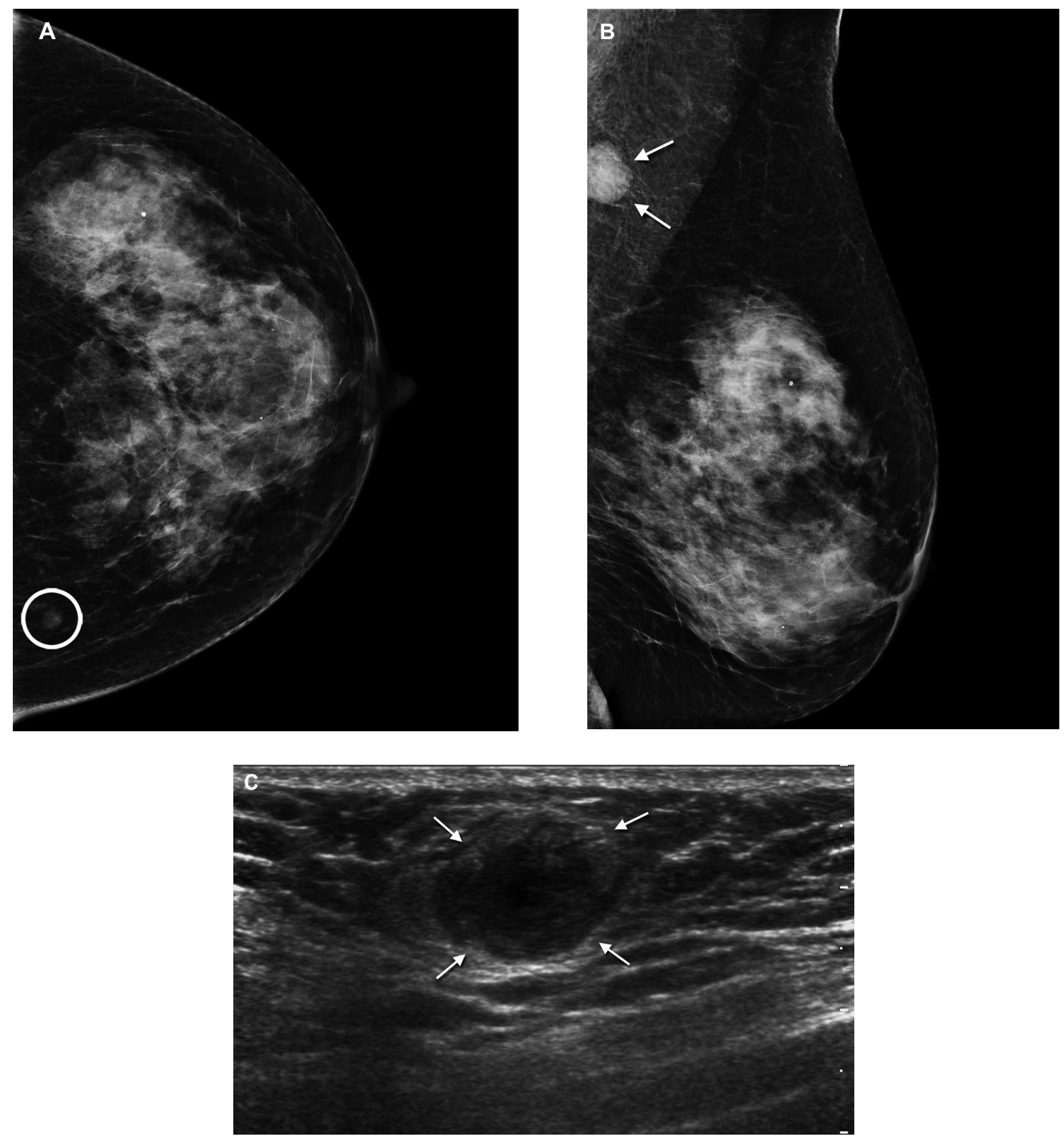

Figure 4 Plasmacytoma of the breast. Left mammogram shows (A) a small well defined mass (circle) in the left craniocaudal view and (B) an abnormal lymph node (arrows) in the mediolateral oblique view. (C) Ultrasound shows a hypoechoic mass (arrows) with hyperechoic rim.

Treatment for primary breast amyloidosis is surgical excision of the affected area. Treatment for secondary amyloidosis is done by treatment of the underlying systemic disease. ${ }^{45}$

\section{Metastases from other solid organ primaries}

Breast cancer is the most common type of primary malignancy in women, but metastatic spread to the breast from other solid organs, although rare, has been reported ${ }^{51-53}$ and may be the first sign of malignancy. ${ }^{54}$ On the basis of histologic diagnosis in clinical studies, the frequency of metastatic tumors in the breast from extramammary malignancies has been estimated to range from $0.2 \%$ to $1.3 \%{ }^{55}$ In a review from the Royal London Hospital of secondary neoplasms from other solid organs that metastasized to the breast, Georgiannos et al ${ }^{56}$ reported that, over 90 years, metastases to the breast were 
A
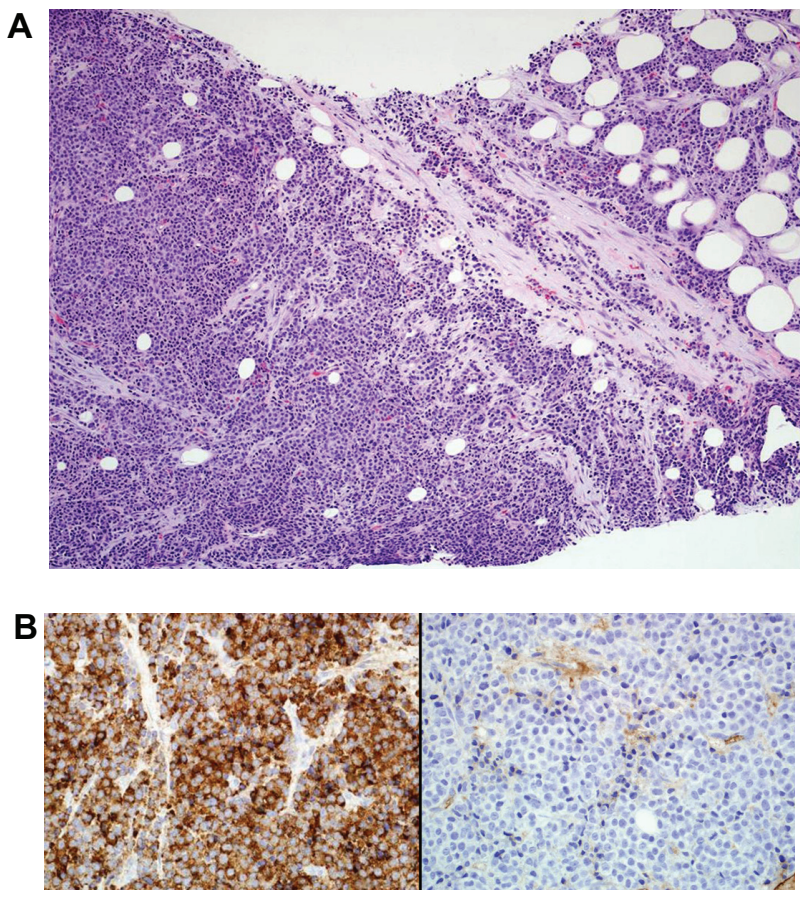

Figure 5 Breast biopsy. (A) Breast biopsy shows plasma cell neoplasm (hematoxylineosin stain, original magnification 200x). (B) Left, $\kappa$ immunoglobulin antibody light chain stain is positive (original magnification $400 \times$ ) and, right, $\lambda$ immunoglobulin antibody light chain stain is negative (original magnification $400 \times$ ).

found to emanate from primary lung cancer, melanoma, or gastric, renal, endometrial, pancreatic, esophageal, and thyroid cancers (in descending order of frequency).

Williams et $\mathrm{al}^{57}$ found in a series of patients that a single mass was identified on mammography in $39.5 \%$ of patients and that multiple masses were identified in $33.7 \%$ of patients. However, of those patients who underwent breast imaging, $16.3 \%$ had mammograms with no abnormal findings. The recommended diagnostic approach to metastases from other solid organ primaries is core biopsy for tissue diagnosis.

Immunohistochemistry is considered beneficial in distinguishing between primary breast cancers and metastases from other organs. ${ }^{57}$ In addition to findings of standard and specialized stains, estrogen-, progesterone-, and HER-2 receptor-negative findings can help to differentiate metastatic tumors from primary breast cancers.

Treatment is focused on management of the primary cancer rather than on the metastatic lesion to the breast. However, Williams et a ${ }^{57}$ noted that if the metastatic disease burden is low, lumpectomy might be considered.

\section{Conclusion}

In summary, this review reports on breast lesions associated with systemic disorders and details the clinical presentation, imaging findings, pathologic findings, and treatment.
Although such presentations are rare, an awareness of these associations and knowledge about the diagnosis and treatment of patients with such breast lesions is critical to determining appropriate evaluation and treatment. However, breast cancer always needs to be strongly considered in the differential diagnosis of breast abnormalities in such patients.

\section{Acknowledgments}

We would like to acknowledge the Division of General Internal Medicine, Mayo Clinic, for their support. We would also like to acknowledge Carol Reynolds, MD, Division of Anatomic Pathology, Mayo Clinic, for her kind assistance.

\section{Disclosure}

The authors have no conflicts of interest to disclose.

\section{References}

1. Ely KA, Tse G, Simpson JF, Clarfeld R, Page DL. Diabetic mastopathy: a clinicopathologic review. Am J Clin Pathol. 2000;113(4):541-545.

2. Gouveri E, Papanas N, Maltezos E. The female breast and diabetes. Breast. 2011;20(3):205-211.

3. Kudva YC, Reynolds C, O'Brien T, Powell C, Oberg AL, Crotty TB. Diabetic mastopathy, or sclerosing lymphocytic lobulitis, is strongly associated with type 1 diabetes. Diabetes Care. 2002;25(1):121-126.

4. Hunfeld KP, Bassler R. Lymphocytic mastitis and fibrosis of the breast in long-standing insulin-dependent diabetics: a histopathologic study on diabetic mastopathy and report of ten cases. Gen Diagn Pathol. 1997; 143(1):49-58.

5. Sotome K, Ohnishi T, Miyoshi R, et al. An uncommon case of diabetic mastopathy in type II non-insulin dependent diabetes mellitus. Breast Cancer. 2006;13(2):205-209.

6. Seidman JD, Schnaper LA, Phillips LE. Mastopathy in insulin-requiring diabetes mellitus. Hum Pathol. 1994;25(8):819-824.

7. Thorncroft K, Forsyth L, Desmond S, Audisio RA. The diagnosis and management of diabetic mastopathy. Breast J. 2007;13(6):607-613.

8. Janigan DT, Hirsch DJ, Klassen GA, MacDonald AS. Calcified subcutaneous arterioles with infarcts of the subcutis and skin ("calciphylaxis") in chronic renal failure. Am J Kidney Dis. 2000;35(4): 588-597.

9. Benes K, Olubowale O, Stephenson T, Fernando M. Non healing ulcer of the breast due to calciphylaxis. Breast J. 2009;15(5):541-542.

10. Morris DJ, Fischer AH, Abboud J. Breast infarction after internal mammary artery harvest in a patient with calciphylaxis. Ann Thorac Surg. 1997;64(5):1469-1471.

11. Rashid A, Haj Basheer M, Khan K. Breast necrosis following harvest of internal mammary artery. Br J Plast Surg. 2004;57(4):366-368.

12. Wong MS, Kim J, Yeung C, Williams SH. Breast necrosis following left internal mammary artery harvest: a case series and a comprehensive review of the literature. Ann Plast Surg. 2008;61(4):368-374.

13. Campanino PP, Tota D, Bagnera S, et al. Breast calciphylaxis following coronary artery bypass grafting completely resolved with total parathyroidectomy. Breast $J$. 2010;16(5):544-547.

14. Bukhman R, Scheri RP, Selim MA, Baker JA. Sonography in the identification of calciphylaxis of the breast. J Ultrasound Med. 2010;29(1): 129-133.

15. Krell JM, Sanchez RL, Solomon AR. Diffuse dermal angiomatosis: a variant of reactive cutaneous angioendotheliomatosis. J Cutan Pathol. 1994;21(4):363-370.

16. McLaughlin ER, Morris R, Weiss SW, Arbiser JL. Diffuse dermal angiomatosis of the breast: response to isotretinoin. $J$ Am Acad Dermatol. 2001;45(3):462-465. 
17. Yang H, Ahmed I, Mathew V, Schroeter AL. Diffuse dermal angiomatosis of the breast. Arch Dermatol. 2006;142(3):343-347.

18. Villa MT, White LE, Petronic-Rosic V, Song DH. The treatment of diffuse dermal angiomatosis of the breast with reduction mammaplasty. Arch Dermatol. 2008;144(5):693-694.

19. Wahner-Roedler DL, Swanson EA, Morton MJ, Reynolds C. Diffuse dermal angiomatosis of the breast [Abstract]. 33rd Annual Symposium of the American Society of Breast Disease Book of Abstracts. April 2-4, 2009:11.

20. Draper BK, Boyd AS. Diffuse dermal angiomatosis. J Cutan Pathol. 2006;33(9):646-648.

21. Rotter MA, Schnatz PF, Currier AA Jr, O'Sullivan DM. Breast arterial calcifications (BACs) found on screening mammography and their association with cardiovascular disease. Menopause. 2008;15(2) 276-281.

22. Kadotani Y, Enoki Y, Itoi N, Kojima F, Kato G, Lee CJ. Giant cell arteritis of the breast: a case report with a review of literatures. Breast Cancer. 2010;17(3):225-232.

23. Hinze S, Hart YM, Adams RF. Lumpy breasts and headache: a crucial ultrasound. Br J Radiol. 2011;84(1000):386-387.

24. Blockmans D, Bley T, Schmidt W. Imaging for large-vessel vasculitis. Curr Opin Rheumatol. 2009;21(1):19-28.

25. Khalil HH, Marsden J, Akbar N, Gordon P, Roberts J, Schulte KM. Polyarteritis nodosa of the breast: presentation and management. Int $J$ Surg. 2009;7(5):446-450.

26. Yamashina M, Wilson TK. A mammographic finding in focal polyarteritis nodosa. Br J Radiol. 1985;58(685):91-92.

27. Ng WF, Chow LT, Lam PW. Localized polyarteritis nodosa of breast: report of two cases and a review of the literature. Histopathology. 1993; 23(6):535-539.

28. Allende DS, Booth CN. Wegener's granulomatosis of the breast: a rare entity with daily clinical relevance. Ann Diagn Pathol. 2009;13(5): 351-357.

29. Comas AG, Diana CA, Crespo CC, Cebollada MM, Linan MA, Vila JV. Wegener's granulomatosis presented as recurrent breast abscess. Breast J. 2010;16(1):82-84.

30. Neralic-Meniga I, Ivanovi-Herceg Z, Mazuranic I, et al. Wegener's granulomatosis of the breast. Wien Klin Wochenschr. 2006;118(3-4): $120-123$

31. Panzacchi R, Gallo C, Fois F, et al. Primary sarcoidosis of the breast: case description and review of the literature. Pathologica. 2010;102(3): 104-107.

32. Takahashi R, Shibuya Y, Shijubo N, Asaishi K, Abe S. Mammary involvement in a patient with sarcoidosis. Intern Med. 2001;40(8) 769-771.

33. Gisvold JJ, Crotty TB, Johnson RE. Sarcoidosis presenting as spiculated breast masses. Mayo Clin Proc. 2000;75(3):293-295.

34. Hermann G, Nagi C, Mester J, Tierstein A. Unusual presentation of sarcoidosis of the breast. Br J Radiol. 2008;81(969):e231-e233.

35. Kinonen C, Gattuso P, Reddy VB. Lupus mastitis: an uncommon complication of systemic or discoid lupus. Am J Surg Pathol. 2010;34(6): 901-906.

36. Summers TA Jr, Lehman MB, Barner R, Royer MC. Lupus mastitis: a clinicopathologic review and addition of a case. Adv Anat Pathol. 2009;16(1):56-61.

37. Tewari M, Shukla HS. Breast tuberculosis: diagnosis, clinical features and management. Indian J Med Res. 2005;122(2):103-110.
38. Lin TL, Chi SY, Liu JW, Chou FF. Tuberculosis of the breast: 10 years' experience in one institution. Int J Tuberc Lung Dis. 2010;14(6): 758-763.

39. Wong WW, Schild SE, Halyard MY, Schomberg PJ. Primary nonHodgkin lymphoma of the breast: the Mayo Clinic experience. $J$ Surg Oncol. 2002;80(1):19-25.

40. Sabate JM, Gomez A, Torrubia S, et al. Lymphoma of the breast: clinical and radiologic features with pathologic correlation in 28 patients Breast J. 2002;8(5):294-304.

41. Jennings WC, Baker RS, Murray SS, et al. Primary breast lymphoma: the role of mastectomy and the importance of lymph node status. Ann Surg. 2007;245(5):784-789.

42. Brem RF, Revelon G, Willey SC, Gatewood OM, Zeiger MA. Bilateral plasmacytoma of the breast: a case report. Breast J. 2002;8(6) 393-395.

43. Surov A, Fiedler E, Holzhausen HJ, Ruschke K, Schmoll HJ, Spielmann RP. Metastases to the breast from non-mammary malignancies: primary tumors, prevalence, clinical signs, and radiological features. Acad Radiol. 2011;18(5):565-574.

44. International Myeloma Working Group. Criteria for the classification of monoclonal gammopathies, multiple myeloma and related disorders: a report of the International Myeloma Working Group. Br J Haematol. 2003;121(5):749-757.

45. Charlot M, Seldin DC, O’Hara C, Skinner M, Sanchorawala V. Localized amyloidosis of the breast: a case series. Amyloid. 2011;18(2): $72-75$.

46. Deolekar MV, Larsen J, Morris JA. Primary amyloid tumour of the breast: a case report. J Clin Pathol. 2002;55(8):634-635.

47. Sahoo S, Reeves W, DeMay RM. Amyloid tumor: a clinical and cytomorphologic study. Diagn Cytopathol. 2003;28(6):325-328.

48. Toohey JM, Ismail K, Lonergan D, Lewis CR. Amyloidosis of the breast mimicking recurrence in a previously treated early breast cancer Australas Radiol. 2007;51(6):594-596.

49. Cao MM, Hoyt AC, Bassett LW. Mammographic signs of systemic disease. Radiographics. 2011;31(4):1085-1100.

50. Wilkinson I, Thomas J. Breast diseases associated with systemic medical disorders. Diagn Histopathol. 2009;15(8):402-408.

51. Akcay MN. Metastatic disease in the breast. Breast. 2002;11(6): 526-528.

52. Lee SK, Kim WW, Kim SH, et al. Characteristics of metastasis in the breast from extramammary malignancies. J Surg Oncol. 2010;101(2): 137-140.

53. Young JL Jr, Ward KC, Wingo PA, Howe HL. The incidence of malignant non-carcinomas of the female breast. Cancer Causes Control. 2004;15(3):313-319.

54. Hamby LS, McGrath PC, Cibull ML, Schwartz RW. Gastric carcinoma metastatic to the breast. J Surg Oncol. 1991;48(2):117-121.

55. Lee AH. The histological diagnosis of metastases to the breast from extramammary malignancies. J Clin Pathol. 2007;60(12):1333-1341.

56. Georgiannos SN, Chin J, Goode AW, Sheaff M. Secondary neoplasms of the breast: a survey of the 20th century. Cancer. 2001;92(9): 2259-2266.

57. Williams SA, Ehlers RA 2nd, Hunt KK, et al. Metastases to the breast from nonbreast solid neoplasms: presentation and determinants of survival. Cancer. 2007;110(4):731-737.
International Journal of Women's Health

\section{Publish your work in this journal}

The International Journal of Women's Health is an international, peerreviewed open-access journal publishing original research, reports, reviews and commentaries on all aspects of women's healthcare including gynecology, obstetrics, and breast cancer. Subject areas include: Chronic conditions (migraine headaches, arthritis, osteoporosis);

\section{Dovepress}

Endocrine and autoimmune syndromes; Sexual and reproductive health; Psychological and psychosocial conditions. The manuscript management system is completely online and includes a very quick and fair peer-review system. Visit http://www.dovepress.com/ testimonials.php to read real quotes from published authors. 